\title{
Compensating Indigenous social and cultural losses: a community-based multiple-attribute approach
}

\author{
Robin Gregory $^{1,2}$, Philip Halteman $^{3}$, Nicole Kaechele ${ }^{4}$, Jana Kotaska and Terre Satterfield ${ }^{2}$
}

\begin{abstract}
Impact evaluations in North America are required to examine not only the economic, environmental, and health effects of activities but also their social and cultural impacts. In practice, however, many important social and cultural effects are often neglected as part of court-sponsored negotiations and decisions by government regulators because they are not represented in terms of economic markets, specific to the decision context, or lack standard measures. This omission is especially significant when determining compensation for Indigenous communities due to restrictions placed on their fundamental connection to traditional lands and the negative impacts on language, governance, social systems, and well-being that rely on the maintenance of shared, place-based practices. We propose a comprehensive, multiattribute approach for estimating compensation to Indigenous communities and summarize results from a case-study application in two Indigenous Dene Nations. In a final section we discuss the broader implications of adopting a more accurate depiction of impacts and a consistent, principles-based approach to calculating compensation payments that is more respectful of the losses experienced over time by many Indigenous communities as the result of encroachments onto their traditional territories.
\end{abstract}

Key Words: compensation; cultural; environment; Indigenous; social

\section{INTRODUCTION}

Indigenous communities in North America and worldwide have experienced significant losses, including forced relocations from and physical incursions onto their traditional territories. In many cases these direct impacts on the land and local ecosystems have been responsible for a wide range of cascading economic, environmental, social, cultural, spiritual, and health impacts on Indigenous communities. The source of these impacts takes many forms: urban settlements, resource extractions, infrastructure developments such as hydroelectric dams or pipelines, and the far-reaching impacts of climate change.

Under both Canadian and U.S. legislation, a wide range of impacts must now be addressed as part of project assessments such as environmental impact assessments (EIA); these include economic, environmental, social, cultural, and health-related effects (Office of the President of the United States 1981, Government of Canada 2012). In response, governments, industries, and Indigenous peoples are establishing new partnerships to address how current and proposed activities on traditional territories are implemented. Many of these initiatives reflect insights coming from impact-benefit agreements, project mitigation recommendations, and analyses of cumulative effects.

Increased attention is also being given to compensation for damages due to past actions. Within this context, adverse effects on Indigenous communities, often based in changes to ecosystems or limitations in access related to developments on traditional territories, are typically grouped into two categories, tangible (or material) and intangible (or nonmaterial). Tangible losses include both economic and environmental effects: increased health care costs due to higher morbidity, loss of human life, and reduced length of working life; material uses of natural resources, such as through fishing, hunting, or trapping; economic opportunities; air and water quality; and ecosystem services, such as regulation of floods and carbon sequestration. Intangible or nonmaterial losses include adverse impacts on social relations, cultural practices and identity, governance systems, and nonphysical health, e.g., anger, trauma, shame. Impacts on identity and wellbeing, including spiritual well-being, due to disruption of landbased practices and the relations and knowledge that accompany these include the loss or disruption of ceremonial practices and knowledge systems as well as effects on family and social status (Satterfield et al. 2013).

The dominant paradigm for assessing either the experienced impacts of past actions or the predicted impacts of a proposed action is that of cost-benefit analysis (CBA), which fundamentally rests on the assumption of market-based analogies for determining gains or losses (Freeman 2003). In recent years the limitations of this paradigm have been widely discussed, from the broad perspective of pricing nonmarket effects (Ackerman and Heinzerling 2002, Satz 2010) as well as the specific context of valuing Indigenous losses (Gregory and Trousdale 2009, Satterfield et al. 2013). In particular, CBA approaches emphasize the tangible economic, health, and environmental changes that are more easily quantified and measured in terms of monetary equivalents. As a result, many of the more intangible and difficult to measure social, cultural, and nonphysical health effects, including impacts specific to Indigenous groups or nations, have been either ignored completely or extrapolated through questionable proxies (Turner et al. 2008).

In response, recent impact assessments have begun to identify a more comprehensive range of effects (Esteves et al. 2012) and have given greater attention to assessments of the overall health and well-being of individuals (Graham et al. 2018). These changes are welcomed, but in many ways continue to fall short of what is

${ }^{1}$ Decision Research, ${ }^{2}$ Institute for Resources, Environment and Sustainability, University of British Columbia, ${ }^{3}$ Compass Resource Management,

${ }^{4}$ RIO Project Management 
needed to assess the impacts of long-term changes in the practices and lifestyle opportunities of Indigenous communities. One reason is the fundamental connection to sustainable land practices that characterizes most Indigenous communities: language, governance, livelihood, and health are closely attuned to access and use of traditional homelands (Berkes 1999, Gilani et al. 2018). Moreover, the powerful sense of community and stewardship common to peoples whose relationships to places and histories are many generations deep has the implication that impact measures based on changes currently being experienced will not adequately reflect many of the most important community-wide and intergenerational impacts (Satterfield et al. 2013). Finally, many social and cultural impacts lack standard, familiar measures, which results in their omission from most guidelines for project assessment and, even when they are included, both their definition and the associated data collection are often ad hoc and of limited relevance to the people whose lives have been altered (Borrows 2002, Gregory et al. 2016).

In the work reported here we seek to address these limitations and propose a general approach for estimating compensation to Indigenous communities that more accurately characterizes and evaluates both tangible and intangible losses, including the multiple dimensions of economic, social, health, spiritual, and cultural losses. Its theoretical basis is multiattribute assessment methods, developed across the decision and social sciences (Keeney and Raiffa 1993). Information about the nature and extent of impacts is based on interviews with community members as well as evidence and technical data drawn from government reports, EIAs, and traditional use studies.

\section{LEGAL AND METHODOLOGICAL CONSIDERATIONS}

Although many compensation settlements awarded in recent decades, to both Indigenous and non-Native claimants, have recognized a range of noneconomic social and cultural impacts as well as both physical and mental health effects, there remains a disturbing lack of logic and transparency to the payments awarded in these cases. Confidential negotiations typically have resulted in a lack of public records describing either the assumptions or methodologies underlying the settlements. As a result, a reasonable conclusion is that the specific dollar figures in most cases owe more to the ad hoc negotiation talents and powers of the various legal parties than to the application of a consistent logic. This leaves claimants dependent on the skills of their legal advisors and negotiators, with limited precedent established to inform either public discourse or future negotiation and litigation processes. We suggest that it is necessary to construct a more consistent basis for compensation agreements by looking to foundational principles and legal precedent, with reference to a range of widely used analytic methods and approaches. Together, these have the potential to create a more defensible and transparent basis for determining a fair level of monetary payments for Indigenous losses across multiple contexts.

\section{Compensation principles}

Compensation for losses should reflect legal precedent informed by principles held as just by society. In the case of Indigenous peoples, compensation must also reflect the worldviews and governance system held by the community or nation, which includes the recognition that "an over-emphasis on the imperatives of commerce may ultimately provide an unfair basis for determining a compensation amount" (Litchfield 1999:256). Principles include that compensation awarded to Indigenous peoples for the loss of traditional lands or restrictions on traditional practices should,

- Reflect a defensible logic and be nonarbitrary, so that arguments are transparent, repeatable, and meaningful;

- Recognize the many limitations associated with monetization of individual and community losses experienced by a First Nation (P. Burke 2002, unpublished manuscript);

- Include both economic and noneconomic losses, keeping in mind that Indigenous societies often maintain a relationship with their territories and share important cultural values and practices distinct from those of mainstream society (Berkes 1999). Specifically, consider the inclusion of compensation for mental distress and other psychological impacts associated with the loss, diminishment, or disruption of ancestral lands, traditional practices, and rights without consent;

- Account for temporal considerations by translating losses experienced in the past or future into commensurate terms so they can be evaluated alongside current losses;

- Include the understanding that payments for losses are not solatium: that is, they relate not to damage for hurt feelings but to far more consequential damages;

- Ensure that accurate facts are determined from experts and relevant documents but also ensure that written and oral information sources acknowledge the experience and perceptions of community members (Kotaska 2013);

- Consider and carry forward $100 \%$ of losses incurred, quantified in the terms of the year they were incurred and adjusted for inflation (Specific Claims Tribunal Canada 2016); and

- Reflect a current, up-to-date understanding of the responsibilities of government to compensate Indigenous communities for past and ongoing losses, notwithstanding historical precedents and previous judgments that may not reflect current evaluation methods or current social standards of fairness and justice.

\section{Compensation precedents}

Understanding the logic of previous compensation awarded for economic, social, health, and cultural losses is helpful: it can contribute to the creation of a defensible logic for compensation payments, it suggests underlying principles of fairness, and it encourages the adoption of consistent methodologies. In addition, knowledge of comparable cases can serve to highlight potential prejudice or bias in awards because it highlights the type and range of damages, helping to ensure that any specific compensation payment is reflective of the overall severity of the impacts suffered and the number of people experiencing the loss.

With this context in mind, we briefly summarize several recent compensation awards for damages experienced by Indigenous and non-Indigenous people. 
- Compensation was awarded by the Federal Court of Australia (2016) for the removal of land rights from Indigenous title holders and "loss of traditional access and use of the land." The Court awarded the Ngaliwurru People and the Nungali People A $\$ 512,400$ for economic loss (plus A $\$ 1,488,261$ in interest) and A $\$ 1.3$ million for cultural loss, referred to as pecuniary in nature, i.e., a real and genuine loss, rather than a solatium payment. Two main reasons for the compensation award were stated: (a) construction undertaken by the local government affected the community's "capacity to conduct ceremonial and spiritual activities," which "caused clearly identified distress and concern," and (b) the government's actions led to a "failed responsibility for the obligation, under the traditional laws and customs, to have cared for and looked after that land" (High Court of Australia 2019). The High Court of Australia subsequently reduced the award for economic loss, but upheld the award of A\$1.3 million for cultural loss, with the final award totaling A $\$ 2.5$ million (High Court of Australia 2019).

- Fatal accident schedules, established in several Canadian provinces, set criteria for determining the level of payments to be made by government to survivors even though the Courts clearly recognize that no amount of money can truly compensate a survivor for the loss of a loved one. In Saskatchewan, for example, payments of Can\$60,000 to the spouse of the deceased person and Can\$30,000 to a parent or child are now mandated. We note that, in the course of our community interviews, several members made the analogy that the loss of a portion of a First Nation's ancestral lands is akin to the loss of a loved one.

- In September 2019, the Canadian government was ordered to pay approximately Can $\$ 40,000$ to each Indigenous child placed in the off-reserve welfare system, with some payments also being made to their parents and grandparents. The total amount of compensation payments is estimated to exceed Can\$1 billion.

- In May, 2018 the Canadian Federal Court approved an Can\$875 million settlement as part of compensation for what has come to be known as the "Sixties Scoop," when Indigenous children were involuntarily removed from their families and homes.

- In the United States, compensation was awarded to victims of abuse from Catholic priests (see Elie 2019). In one case involving four boys who were sexually abused by a religious educator at their church in New York City, the Diocese of Brooklyn agreed (in 2018) to a settlement of US\$27.5 million.

- In 2005, Canada awarded compensation (approved by Cabinet 10 May 2006) to Indigenous children forced to attend residential schools for the damages suffered while in attendance; however, the amounts specifically excluded the collective and intergenerational harms that arose from the conduct of residential schools. Payments were based on a set amount of Can $\$ 10,000$ for the first year in attendance or any part thereof, and Can $\$ 3000$ for each additional (or part) year.

\section{Approaches to determining compensation}

Although the term "compensation" denotes full money equivalence, we recognize that this is often neither logical nor possible. Monetary compensation cannot fully address or "make whole" adverse impacts on the governance, culture, society, environment, economies, knowledge, or health of Indigenous communities that have been experienced over many decades, any more than postaccident monetary compensation for a severed leg or the loss of a spouse can fully compensate or make whole the injured party. However, the term is widely used in reference to actions of governments that seek to address losses experienced by Indigenous communities through the award of monetary payments. Our approach makes use of techniques from economics to describe and value economic losses, approaches from sociology and anthropology to identify and describe the multiple dimensions of social and cultural losses, and methods drawn from psychology, negotiations, and the decision sciences to elicit from community members fair and unbiased representations of the relative values of the major categories of losses.

Economics, and in particular a range of economic methods classed as variants of cost-benefit analysis (Johansson and Kristrom 2018), offers several approaches for determining compensation for both material and nonmaterial losses. Typically these assign values to costs and benefits relative to existing markets. If no market exists, the existence of "a contingent" market is assumed and monetary values are assigned to things not normally bought or sold (Freeman 2003). This assignation of value relies on one of several methods: (a) willingness to pay (WTP) to achieve a gain in the object in question, e.g., a unit of moose habitat; (b) inferred value through travel-costs, e.g., travel to a recreational site; (c) hedonic value, based on gains or losses in value associated with the attributes of an experience or object. Other methods are drawn from stated-choice or stated-preference models; these ask individuals to choose among several different outcomes and, on the basis of the individual's selection and relative weighting of various dimensions, monetary values are assigned to the selected outcomes (Haener et al. 2001).

Despite their prevalence in economic research and usefulness in estimating some types of conventional market and nonmarket losses, these methods present conceptual and methodological flaws that severely limit their utility for intangible losses experienced by Indigenous peoples (U.S. Department of Interior 2018). For example, contingent valuation approaches ignore the fact that creating market surrogates for unpriced items often makes no logical sense and may be considered disrespectful (Ackerman and Heinzerling 2002). In addition, surveyed individuals will often construct their preferences, i.e., their willingness to pay, quickly and inconsistently in response to irrelevant cues (Lichtenstein and Slovic 2006). Similarly, statedchoice approaches require individuals to express preferences for difficult-to-compare or incommensurate items, i.e., the value of a life as compared to the value of a job, and the choices offered to participants often fail to describe or incorporate key dimensions of value. Moreover, economic methods rely on assessments from the perspective of an individual, whereas it is often more appropriate to view Indigenous cultural and social phenomenon from a community perspective, in part because so many ecosystem services and resources from the land are openly shared (Turner et al. 2008, Gregory et al. 2016). 
Sociology and anthropology offer a range of approaches to identify and evaluate social, cultural, and health impacts on individuals and communities from experienced losses. One of the most relevant sources of information is traditional use studies, which provide descriptions of the traditional practices of an Indigenous community and typically include extensive information from interviews with elders and community leaders (Tobias and Richmond 2014). The increased attention given to the importance of social and cultural impacts has resulted in a growing collaboration among anthropologists, planners, ecologists, and decision scientists seeking to grapple with the many challenges involved in thinking about cultural consequences of environmental changes (often based in climate change) in a way that respects and is meaningful to those impacted and provides evidence that can influence government or legal decision makers (Ogden and Innes 2009, Bessette and Gregory 2020). These collaborations have resulted in a rich body of studies, focused on developing a better understanding of cultural worldviews, cultural symbols, and ways to evaluate changes in cultural practices (O'Faircheallaigh 2008, Donatuto et al. 2011, Chan et al. 2012).

Psychology offers important insights regarding how people typically express values and preferences as a function of information processing that is efficient yet prone to known biases (Brest and Krieger 2010, Kahneman 2011). These considerations, well known to behavioral decision scientists, include the following:

- Awareness that people often do not know how to think about or evaluate many nonmarket and less tangible items, which can have the unintended effect that familiar types of losses, e.g., adverse economic impacts, receive more attention from government staff and consultants than less familiar losses, e.g., adverse effects on spiritual or ceremonial practices;

- Recognition that adjustments to some types of changes (positive or negative) can take place over time, whereas other, nonmarginal changes are sufficiently severe that adjustments cannot successfully be made;

- Awareness that worldviews and political beliefs often lead (rather than follow) the interpretation of factual information about the consequences of an action, which can lead to polarization and an overreliance on self-supporting facts and data;

- Awareness of the prominence effect (Tversky et al. 1988), which leads to an overreliance on a single, most easily justified dimension of loss, e.g., economic losses, rather than the full range of impacts; and

- Awareness of tendencies associated with strategic bias, whereby judgments regarding the relative importance of information can be skewed to the extent that participants seek to influence results.

The decision sciences respond to problems of information processing by emphasizing a multiple-attribute approach to the evaluation of impacts. Methods are based on decision analysis (von Winterfeldt and Edwards 1986, Keeney and Raiffa 1993), behavioral decision theory (Slovic 2010, Kahneman 2011), and negotiation analysis (Raiffa 2002). Together, these approaches have been used to support a wide variety of challenging valuation contexts that require identifying the impacted values, generating and comparing different alternatives, and/or establishing monetary equivalents for intangible values (Gregory et al. 2012, Shepherd et al. 2015). Most relevant are cases when methods from the decision sciences have been applied in Indigenous communities to estimate cultural, social, and health impacts stemming from petroleum developments, flooding of traditional territory by dams, climate change, or pipeline construction (Christie et al. 2018, Failing et al. 2013, Gregory and Trousdale 2009).

A basic element in a decision analysis or other structured decisionmaking approach to determining compensation is the explicit deconstruction of impacts, including (in the case of Indigenous communities) cultural and social values, into their component dimensions. These are discrete, nonoverlapping categories of value based on how any designated group characterizes or classifies their losses. For example, the loss of the ability to hunt moose represents several important values or categories of losses: food sustenance for the winter, the opportunity for older generations to teach hunting and food processing skills to youth, the inability to continue seasonal rounds, the loss of opportunities for family members to spend meaningful time together, the loss of the ability to provide for one's family and community, and the loss of ways of being deemed fundamental to identity and a community's experience of life and place (Coulthard 2014, Sharp 2004). For members of Indigenous communities these different categories of loss typically are interwoven and add up to a social and cultural whole that is "more than the sum of its parts."

\section{CASE STUDY: EXCLUSION FROM TRADITIONAL LANDS AND LOSS OF TRADITIONAL PRACTICES}

\section{Background}

This case study focuses on the nature and magnitude of losses experienced by two Indigenous communities in north-central Canada as a result of specific actions taken by the Government of Canada (GOC). Both communities are Denesuline (Dene) First Nations, Indigenous peoples whose members have lived in the boreal regions of central and western Canada for thousands of years. As with many other Dene peoples, a larger group that includes the Navajo and Apache Nations of the American southwest, they are traditionally hunters, fishers, and harvesters of native plants; many community members continue to practice these activities and to live in a close relationship with the land (Brody 1981).

In the early 1950s, the GOC took control of a large parcel of these Nations' traditional territories for the purpose of establishing a military weapons testing facility. The lands are part of the 1906 Treaty 10 agreement (Office of the Treaty Commissioner 1907), with protection granted to the signatories "to pursue their usual vocations of hunting, trapping and fishing throughout the territory" (Indian Claims Commission 1995). The governmentappointed Commissioner, J. A. J. McKenna, wrote at the time that "The Indians seemed afraid ... that their liberty to hunt, trap, and fish would be taken away or curtailed, but were assured by me that this would not be the case" (Indian Claims Commission 
1995). Some Nations did receive limited compensation, in acknowledgement of the loss of their ability to provide themselves with a land-based livelihood, but others, including these two Dene Nations, did not. After years of court action initiated by the Nations, the GOC in 2019 acknowledged its duty to pay monetary compensation to several communities not included in the initial settlements. This meant that the parties faced the difficult challenge of determining what types of damages merited compensation and what level of payment would be fair.

We were asked, as researchers and analysts, by the two Dene Nations and their legal counsel to help construct a logical and transparent process for determining compensation payments owing to the Nations for the full range of losses (including landbased economic, social, and cultural effects) caused by the establishment and ongoing operations of the military weapons range (WR). Our task was twofold. First, we had to place the information regarding these impacts within a multidimensional evaluation framework that faithfully represents the nature and magnitude of losses experienced by community members. In agreeing to undertake this task we recognized (a) that as nonDene outsiders, we would need to openly acknowledge the limitations of our understanding (Wilson 2008) and (b) that full compensation for the experienced losses is impossible, in part because of the nearly seven decades since establishment of the military facility. Second, we had to organize the information regarding impacts in such a way that quantitative calculations of monetary compensation would be viewed by governments (including both the Dene Nations and Canada) and the Courts as rigorous, replicable, and unbiased.

\section{Description of impacts and losses}

The principal categories of losses to the two Dene communities were derived from and developed on the basis of interviews and then discussed and verified with community members. Data sources include one-on-one interviews, small groups, e.g., meetings with Chief and Band Councils, stories shared with us by elders and council or senate members, traditional use and environmental studies, as well as reports based on earlier meetings with northern Canadian Dene communities; and reports and memos (going back to the early 1950s) written by provincial and federal government staff. Members of the project team made two visits to the communities, in August and September of 2019. Both visits included discussions to characterize and describe the impacts assessed in this report; the second meeting and subsequent analyses conducted by the project team focused on the estimates of monetary compensation for social and cultural land-based losses.

We briefly describe the following five major categories of losses, identified through discussions with community members.

Trauma, fear, and related physical effects on health and wellbeing

Three primary sources of impact on health and well-being have been significant for members of both Dene First Nations. The first is a prevailing trauma and fear related to the ongoing loss of access to land used for a range of economic, social, cultural, and spiritual practices (Kirmayer et al. 2014). Community members noted that this loss was reinforced and made worse by the irregular but ongoing noise associated with air flights and testing of weapons. The Chief of one nation told us that establishment of the WR had "put fear into people's hearts" because they were told "you could step on a bomb ... so the connection to the land was severed by fear." Another Council member told us "We have trauma now and that is created by all the fear," and an older member of the community said that "Fear was instilled into us. We lost lots of opportunities, because of that fear."

The second element is anger at the way in which Canada has treated the two communities over the past 65 years. Underlying this is a lack of consultation related to the change in the relationship of the communities to their land, which abruptly shifted from free access to complete exclusion: one week community members enjoyed free access to the WR area, the next (and for decades afterward) they did not. A member of one community said, "I don't know why they didn't tell the people around here ... they just took the land like that." This created a strong sense of injustice, made stronger by a lack of clarity over the length of time that access restrictions would remain in place.

The third component is an overall decline in physical health and well-being and the far reaching, cumulative, and ongoing lifestyle changes, e.g., diet and exercise, directly imposed on community members. Psychology research points to such dislocation, and the inability to either pursue customary activities or belong to groups that have provided meaning and identity, as an important source of marked declines in physical well-being and a leading cause of increases in rates of addiction among community members (Alexander 2008).

\section{Cultural practices, identity, and knowledge}

Cultural knowledge includes both abstract knowledge, in the form of epistemologies and worldviews, and practical knowledge or skills (Sahlins 1999). Epistemologies include knowledge of why and how something is or came into being as well as the logic underpinning a truth or belief. Worldviews include systems or ways of perceiving and classifying the physical, human, and nonhuman world and the social obligations that accompany these orderings of the world. Practical knowledge and skills represent that knowledge borne of practice, including maintaining and perpetuating collective habits or ways of being that are learned and transmitted by the constant doing and redoing of important routines (Simpson 2014).

The importance of land to Indigenous peoples has been well documented in case law, as stated in the ruling by Canada's Supreme Court in Delgamuukw v. British Columbia: "The relationships that Aboriginal peoples have with the land cannot be understated. The land is the very essence of their being. It is their very heart and soul.... This is a perspective that is foreign to and often difficult to understand from a non-Aboriginal viewpoint" (Supreme Court of Canada 1997). Yet, as we repeatedly heard from community members, the GOC sought to actively come between the Nations and their traditional lands. The loss of the ability to continue traditional hunting, fishing, land management, and plant harvesting practices and to use and pass on knowledge in the places where this had always taken place results in direct and consequential impacts on cultural identity, knowledge, governance, and social connections (Turner 2005). As a Council member told us "without stories we lose our identity." 


\section{Connection to families, society, and animals}

Land holds direct connections to self-determination and social connections that are foundational for holding together the fabric of many Indigenous Nations. For a Dene community, the shared system of cultural knowledge and narratives is directly linked to the environment and the places where Dene people live. Chiefs and Council members in both Dene Nations spoke repeatedly about how the loss of freedom to move around on the land as they had always done contributed to a fundamental decline in spiritual and cultural well-being among community members. Community leaders, supported by results from health researchers (Thira and McCormick 2012), also link the loss of connection to the land with the unusually high number of youth suicides within their communities.

For Dene, land is considered a relational element, providing essential links to the seasonal round of events that helped maintain stories, relationships, and traditions among families and between villages (Gilani et al. 2018). The importance of the land in reference to social connections can also be analyzed through teachings with specific species. For example, moose is a high protein food essential to the diet of the Denesuline people; however, it is also through the harvesting and processing of moose that knowledge is passed on from Elders to youth and that critical lessons regarding the importance of the lands and waters of the territory are shared (Turner et al. 2008). This lived expression of culture is fundamental to the quality of "being Dene": the skills, knowledge, practices, and routines that make up the fabric of Dene worldviews and sense of identity.

\section{Access to places, knowledge, and trails}

Establishment of the WR led to a near complete loss of access to important historic, spiritual, and burial sites; to trails used by people, animals, and ancestors (described by several community members) as essential for the recognition and preservation of the important intergenerational reality of "footprints." Prior to the imposition of the WR, the area was used extensively by the Dene communities for social, cultural, spiritual, and economic purposes at all times of year (Legat 2012). After 1952, a few families were invited to share hunting and trapping areas outside the range, but many others were not. This resulted in an immediate loss of physical, psychological, and spiritual access for many individuals and families, with the effects still felt strongly today by the children and grandchildren of those directly affected in the 1950s. Because place names, stories, maps, and traditional knowledge were not written down but were learned from generation to generation, on the land, loss of access to the places where information was passed on has meant a huge loss of stories and knowledge that lived in specific places. As we were told by an elder: "When you can't go there, it stops you from being what you are."

\section{Household livelihood and related economic losses}

Six main categories of impacts with household economic consequences were identified during our interviews with community members and supported by evidence from previous research, memos from the Indian Affairs Branch written in the 1950s, and studies completed by the GOC. These categories include the following:
- Loss of subsistence hunting and fishing opportunities

- Loss of subsistence plant/berry and domestic harvest opportunities

- Loss of income from domestic/household trapping and other products

- Loss of property such as cabins

- Losses of travel corridors

- Loss of future economic opportunities.

These changes in livelihood are consistent with the impacts experienced by many Indigenous communities, in Canada and other countries, who have lost access to their traditional lands, with losses particularly significant in the context of more highly land-connected and land-dependent communities. We note that, given the diversity of societal changes since the 1950s and the limited time frame for this analysis, the final two categories of losses were excluded from monetary calculations of compensation

\section{CALCULATING MONETARY COMPENSATION FOR SOCIAL AND CULTURAL LOSSES}

\section{Methods overview}

Our approach for calculating monetary compensation for the two Dene nations as the result of the GOC's taking of traditional lands differed in several ways from conventional approaches. The primary difference was that the compensation reflects the multidimensional and values-based categories of losses most significant to the Dene communities in question rather than the categories of economic loss assigned by non-Indigenous experts. In addition, whenever possible, we linked the damages articulated by community leaders and members to ethnographic findings or to reports written by the GOC. This has the dual advantage of improving the transparency of our data sources and findings and enhancing their credibility for non-Indigenous audiences.

Our approach had three main steps. First, we calculated the current value (in 2018 dollars) of economic household livelihood and trade losses experienced between 1953 and the present; as described earlier, this excluded commercial economic activities but included impacts on livelihood related to subsistence household and trade products derived from hunting, fishing, trapping, and plant harvesting. Second, supported by information from community interviews, the ethnographic literature, and analytic methods from the social and decision sciences, we elicited values from community members to rank and weight the categories of loss, i.e., the changes in values experienced over time, according to their relative importance; these weights provided a method for establishing the equivalent value of noneconomic losses relative to losses with clear market equivalents. A separate third step, conducted by the analysts only after the community meetings to avoid strategic bias on the part of participants, calculated the dollar value for each category of loss relative to the calculated household economic impacts.

The assertion of relative importance permits the direct estimation of values for the different categories of social and cultural impacts without the questionable intermediary step (as in cost-benefit analysis, for example) of first translating environmental, social, 
or cultural values into monetary terms. Instead, each category of value is considered in its own right: market-based economic effects measured by dollars, social effects measured by impacts on people within and across communities, and so forth. As discussed extensively in the literature (e.g., von Winterfeldt and Edwards 1986), this development of a multidimensional representation of values follows numerous assumptions underlying determination of an overall functional expression for values (Kirkwood and Sarin 1980) and permits the expression of context-specific consequences relative to each other, based on the type and severity of impacts.

The relative importance of the range of experienced values (or, in this case, types of losses) is then used as the basis for valuation and/or compensation. For example, noneconomic losses that are considered to be twice as important as economic losses, based on the range of experienced effects, are assumed to have a dollar value equivalent to twice the value of the economic losses. The methodology, based in changes in relative values across ranges of effects, is both theoretically supported (in terms of the axioms underlying utility and value functions; see Keeney and Raiffa 1993) and based in common sense; Keeney (1982:815) notes the similarities to "defining a temperature scale by selecting a boiling and a freezing point." When conducted as part of a small-group process, as was done for the results reported here, the methodology also allows for discussions among participants, e.g., to specify the meaning of impact categories, and the refinement of valuations based on any perceived inconsistencies in their assessments across the value categories (Gregory et al. 2012).

\section{Household economic losses to livelihood}

All estimates of losses were made with respect to the mid-1950s establishment of the WR. Other sources of impact, some also leading to economic changes (both adverse and beneficial) on individuals and the two communities, were excluded. This refers to impacts stemming from changes in road access, regional industrial development, medical practices, changes in understanding of the rights of Indigenous peoples, and parallel resource extraction and management activities. As the calculations shown below make clear, we have attempted to isolate and quantify the specific and incremental effects related only to the land losses from the WR on the Dene communities.

Economic losses experienced by households were assessed at the community scale, rather than at the scale of individuals or demographic groups that make up the community. The importance of social connections and the extensive sharing of resources among Dene community members support the notion that although establishment of the WR may have affected people differently, e.g., young vs. old, men vs. women, the across-group and indirect effects on the ability of members to engage in Dene society and practices warranted characterization of the losses at the broader community scale.

The treatment of temporal concerns was critical, given that exclusion of Dene hunters, fishers, and harvesters from traditional lands within the boundaries of the WR has been ongoing since 1953. Household economic losses have been experienced in the past, are currently being experienced, and, assuming the status quo, will be experienced going forward into the future. However, calculations reflect losses only up to the present and do not include any anticipated future losses because we assumed these will be conditional on decisions made with respect to compensation paid by Canada in the near term, i.e., future monetary losses will be reduced to the extent that nearterm compensation is viewed by the communities as appropriate.

Our minimum estimate for the proportion of the communities' losses attributable to the military base was based on the proportion of the area described by a $200 \mathrm{~km}$ radius around each community (a typical range for traditional Dene practices) that overlapped with the area inside the WR. For reasons related both to landscape productivity and ease of access, however, and supported by independent sources of evidence, it was more defensible to assume that any lands to the north were effectively not used by the members of these communities. This "quality adjustment" doubled the proportion of total value coming from the land to which access was excluded.

With these assumptions in mind, and based on GOC reports describing compensation formulas for several Indian Bands at the time the WR was established, the annual per capita value of what someone might reasonably harvest was estimated variously (all in 1952 Canadian dollars) at $\$ 73.33$ per person per year ( $\$ 200$ for game for every fourth person, plus $\$ 70$ for fish for every third person; Department of Indian Affairs 1957), \$200 per person per year (\$2000 for "a competent hunter with nine dependents"; Department of Indian Affairs 1957), and \$235.18 (\$123,500 annually for 523 individuals; Department of Indian Affairs 1952). We used these estimates to provide bounds on the total compensation for lost food resources. A reasonable assumption is that the value of losses to plant harvest and products is approximately $50 \%$ as important as meat values. Note that this proportionality refers only to the value of lost products (berries, roots, rice, medicines, canoe materials, baskets, clothing materials, crafts, hay) and not to other values associated with plants, such as social connections (primarily among women) or a range of cultural practices. Estimates of the total annual trapping income for Bands compensated at the time was $\$ 66,340$ for 523 individuals in 1952 dollars (an annual per capita value of $\$ 126.85$ in 1952; Department of Indian Affairs 1952). We adjusted this value by the Consumer Price Index (CPI; using the "All Items" values) to determine annual losses in each year from 1953 to 2018, and then expressed these annual losses in 2018 dollars by applying the formula described above. The loss of cabins and equipment located within the military base was estimated to be $\$ 39,980$ (per capita value of \$76.44; Department of Indian Affairs 1952); we expressed this one-time loss in 2018 dollars by adjusting for average annual inflation.

We then calculated the value of losses for any given year and for each impact category using estimates developed by GOC in 1952 of the dollar value of specific losses, e.g., of subsistence foods, on a per-person, per-year basis. These values were then adjusted for each year, 1953-2018, using the CPI (Statistics Canada 2019). To then determine the current total value of losses, we used the following three-step calculation:

1. Extrapolating the per-person, per-year values to the full population of the communities to assess community-level losses in each year between 1953 and 2018, using population data from the Indian Restoration System Database (Indigenous and Northern Affairs Canada 2015). 
Table 1. Loss categories used in September 2019 evaluation meetings. WR, military weapons range. The two right-hand columns are left blank because they were to be completed by participants.

\begin{tabular}{|c|c|c|c|}
\hline Type of impact & Summary of impact from WR establishment & $\begin{array}{l}\text { Importance rank of } \\
\text { impact }(1=\text { high, } \\
5=\text { low })\end{array}$ & $\begin{array}{l}\text { Points given to impact } \\
\text { type }(\text { maximum }=100)\end{array}$ \\
\hline Household livelihood & $\begin{array}{l}\text { Household livelihood and related economic losses } \\
\text { (meat, fish, plants) }\end{array}$ & & \\
\hline $\begin{array}{l}\text { Access to places and trails ("where you came } \\
\text { from") }\end{array}$ & Loss of access to places, knowledge, and trails & & \\
\hline $\begin{array}{l}\text { Cultural practices } \\
\text { ("being Dene") }\end{array}$ & Loss of cultural practices, identity, and knowledge & & \\
\hline Social and family connections & $\begin{array}{l}\text { Loss of connections to family, society, and } \\
\text { animals }\end{array}$ & & \\
\hline Well-being, trauma, and fear ("twisted, scared") & $\begin{array}{l}\text { Trauma, fear, related physical effects on health } \\
\text { and well-being }\end{array}$ & & \\
\hline
\end{tabular}

2. Multiplying (1) by the proportion of that value that came from the WR (excluding other areas to which community members retained access).

3. Adjusting (2) for inflation to express the value in 2018 dollars using the formula:

$$
V_{2018}=V_{t} *(1+i)^{n}
$$

where:

a. $V_{2018}$ is the value of annual losses in 2018 dollars

b. $V_{t}$ is the value of losses in year $t$

c. $i$ is the average annual interest rate from years $t$ to 2018, and

d. $n$ is the number of years from $t$ to 2018 .

Total losses for each category were then derived by summing across the years, from 1953 to 2018.

\section{Quantifying the multiple dimensions of loss}

Following our first visit to the Dene Nations, the study team organized input from interviews, incorporated information from previous traditional use studies, and continued to consult with community members. Impacts stemming from exclusion from the WR were ultimately divided into five categories of losses, as described above. These five categories reflect a summary interpretation of the different dimensions of loss experienced by community members.

The five main components of losses were then identified in the two left-hand columns of a table (see Table 1). This allowed the Chief and Council of each Nation, as well as elders and other community members, to (a) review and verify the categorization and description of losses and (b) provide information to us about the relative importance of the different categories of losses (the two right-hand columns, left blank in Table 1 because they were to be completed by participants). Discussions during our second visit helped ensure that all participants, some more comfortable speaking Na-Dené than English, fully understood and were comfortable with the meaning of each of the categories of loss. As expected, these conversations were lively; additions were made to the detailed contents of the five categories, but members agreed that the decomposed impact categories provided comprehensive coverage of the main types of losses experienced by the community from establishment and ongoing operation of the WR.

In order to develop relative importance rankings of changes to the five value categories, community leaders participating in a small-group meeting were asked to assign points describing the importance of each loss, relative to a score of 100 for the most important of the impacts. Participants were asked to think about "the loss related to establishment of the WR that matters the most" or, to provide another perspective, "If you could select just one of the impacts of the WR and make it go away, which would you choose?" (in keeping with other applications of this "swing weighting" method; see von Winterfeldt and Edwards 1986). Community members preferred weighting to directly ranking the different categories and, after discussion, decided to write the five loss categories on the board and then use sticky notes (papers with adhesive backing), each worth 10 points, to weight (or, in the words of one participant, to "vote for") each of the five categories. The more votes assigned to an impact category, the more important changes in that value (directly linked to establishment and operation of the WR) were considered to be. Individuals were free to assign weights as they saw fit, and many decided to halve the 10-point sticky notes to indicate greater, i.e., 5-point, precision in their evaluations.

Summary results of this task are shown in Figure 1, with the importance weights for impacts normalized to reflect results on a 100-point scale. The loss category related to fear, trauma, and a general decline in health was considered to be the most important, receiving $39 \%$ of the total weight assigned to losses, followed (in turn) by connections to society and family, losses in cultural practices, declines in household economic livelihood, and access to places and trails.

\section{Estimating monetary compensation}

Our mandate from the Nations was to conduct a logical, rigorous method for estimating an appropriate amount of monetary compensation for noncommercial losses associated with establishment of the WR. This required the translation of the diverse attributes of value into their monetary equivalents, keeping in mind that this translation, although mandated by Canada for the compensation settlement process, runs counter to the way of thought and the culture of the Dene communities within which we worked. 
Fig. 1. Relative importance weights for the categories of loss.
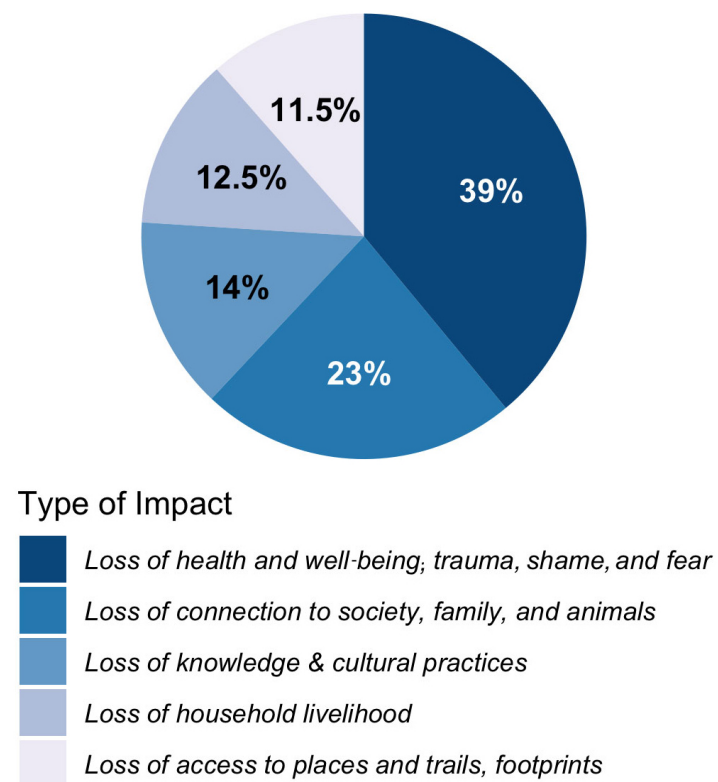

The final step in this procedure was to multiply the dollar-based value associated with household economic losses to livelihood by the relative weights of the other components of loss to estimate the total value of losses (across all five categories). In acknowledgement of the pending status of a compensation agreement between the two Dene communities and the Government of Canada, we provide information about the final compensation calculations only in relative terms (Tables 2 and 3 ). In addition, we note that the calculation of household economic losses related to livelihood is subject to several sources of uncertainty, including the following:

- Community population numbers for 1953-2018 are not precise; other things equal, higher population numbers will increase the total dollar value of experienced losses;

- National economic indicators may neither reflect local conditions nor closely mirror the circumstances of Indigenous communities;

- Assumptions behind the "quality adjustment" for the excluded WR lands, as described above;

- The assumption that annual quantities of resources (fish, meat, plants, and berries) would have remained constant over the past 65 years on a per-capita basis; and

- Records of Indigenous activities kept by GOC during the 1950s, 1960s, and 1970s, which are likely subject to error.

For these reasons, we do not believe that it is either possible or advisable to develop a single precise monetary estimate of total compensation owing to the two communities. In addition, the requirement of providing compensation only in monetary terms for communities that largely operate outside of established economic markets, rather than, for example, also including provisions of land or natural resources, decreases our confidence in the appropriateness of a single estimate. As a result, we argue that a defensible summary "compensation table" for the single category of "trade and household economic losses of livelihood, 1953-2018" should reflect these various sources of uncertainty by including both low and high estimates of compensation as well as a midrange, preferred estimate. In light of the pending status of a settlement agreement, proportional differences for the low and high estimates of effects of the WR on components of household economic livelihood are shown in Table 2 relative to the preferred ("best") estimate for total compensation amounts.

Table 2. Uncertainty in calculations of household economic livelihood losses, 1953-2018.

\begin{tabular}{lccc}
\hline & $\begin{array}{c}\text { Low estimate } \\
\text { (percent of } \\
\text { total) }\end{array}$ & $\begin{array}{c}\text { Preferred } \\
\text { estimate } \\
\text { (percent of } \\
\text { total) }\end{array}$ & $\begin{array}{c}\text { High estimate } \\
\text { (percent of } \\
\text { total) }\end{array}$ \\
\hline $\begin{array}{l}\text { Relative total HH } \\
\text { economic } \\
\text { losses, 1953-2018 }\end{array}$ & 50 & 100 & 179 \\
\hline
\end{tabular}

Calculation of the total compensation owing to the two Dene communities requires combining information from Figure 1 and Table 2. Suppose that, following aggregation of the elements in Table 2, the calculated "preferred estimate" for household economic losses over the period 1953-2018 is equal to \$5 million (an arbitrary amount), with an associated uncertainty range of \$2.5-\$8.95 million (from Table 2). The weighting of the five social, cultural, and household economic values (Fig. 1) provides a basis upon which to calculate values associated with the other four dimensions of loss, implying that total compensation to be paid would be $\$ 40$ million (subject to uncertainty; see Table 3 ). Because the assumptions, methods, and GOC data lying behind these calculations are documented, supporters and critics of the approach as well as legal counsel are free to review the calculations and conduct sensitivity analyses, keeping in mind the dual components of factual information (in this case, largely drawn from GOC and other public-access memos and reports) and values information (in this case, largely drawn from the expertise and experience of Dene community members and supported by ethnographic research).

\section{CONCLUSION AND RECOMMENDATION}

The establishment of a military base by Canada and its continued use over the past 65 years has resulted in the sudden and persistent exclusion of community members from their traditional lands. The GOC has acknowledged responsibility for this exclusion and has agreed to pay fair compensation to the two Dene Nations. Our task has been to provide a logical and comprehensive estimate of the monetary compensation owing to the communities as a result of the directly associated effects from the WR on household economic livelihood and a range of social, cultural, health, and well-being impacts.

The process for estimating monetary compensation summarized in this paper differs from conventional practices in several important ways. Most importantly, we sought to provide a multiattribute, comprehensive description of losses experienced 
Table 3. Relative weights and illustrative compensation amounts including uncertainty. All amounts in Canadian dollars.

\begin{tabular}{|c|c|c|c|c|}
\hline \multirow[t]{2}{*}{ Category of Loss } & \multirow[t]{2}{*}{ Relative weight } & \multicolumn{3}{|c|}{$\begin{array}{l}\text { Illustrative compensation amounts } \\
\text { (\$, millions) }\end{array}$} \\
\hline & & Low $(50 \%)$ & Preferred & $\operatorname{High}(179 \%)$ \\
\hline Trauma, fear, and related physical effects on health and well-being & 3.12 & 7.8 & 15.6 & 27.92 \\
\hline Connection to families, society, and animals & 1.84 & 4.6 & 9.2 & 16.47 \\
\hline Cultural practices, identity, and knowledge & 1.12 & 2.8 & 5.6 & 10.02 \\
\hline Household livelihood and related economic losses & 1.00 & 2.5 & 5 & 8.95 \\
\hline Access to places, knowledge, and trails & 0.92 & 2.1 & 4.2 & 7.52 \\
\hline Total & 8.00 & 20.0 & 40.0 & 71.6 \\
\hline
\end{tabular}

by members of the Indigenous communities that included not only economic impacts on livelihood but also changes to landbased, relational social, cultural, and health values. Second, our main sources of information were the descriptions of loss provided by community residents themselves, whom we consider to be the experts in articulating and describing the losses directly attributable to establishment and operation of the WR. This information was supplemented by government documents and an insightful ethnographic literature. Third, we drew on wellestablished methods from the decision sciences, anthropology, and psychology to avoid the usual presumption of translating only a portion of losses into dollar terms, e.g., through development of market-based analogies; instead, we sought to develop comprehensive descriptions of five major categories of loss and to evaluate these in terms of their relative importance. Fourth, we highlighted behavioral and factual considerations related to addressing uncertainty and several sources of potential judgmental bias in the elicitation and evaluation of the impacted tangible or intangible values. Finally, in the interest of transparency and reliability, we provide the supporting information underlying our calculations so that readers and critics are able to re-examine these assumptions and either conduct sensitivity tests or collect additional information considered relevant to estimation of a fair compensation payment.

Five main categories of loss were developed through consultation with the Dene communities, who provided strong support throughout this project for the community-based evaluation process that led to our estimates of total compensation. Losses related to fear, trauma, and a general loss of health were perceived to be the most important, followed (in turn) by changes to societal and family connections, losses in cultural practices, household livelihood and economics, and access to places and trails. Economic losses related to household livelihood, which constitute the main element of compensation estimates typically developed by government and industry, were rated by community members as only the fourth most important impact category, accounting for $12.5 \%$ (one-eighth) of the total value of losses experienced by community members. This result is significant and underscores both the lack of meaningful consultation on the part of the GOC and its failure to acknowledge or respect a wide range of important social, psychological, and cultural losses associated with loss of access to their traditional lands.

We anticipate that an approach similar to the one described here, recognizing the multiple dimensions of losses experienced by community members, will be applicable to other Indigenous communities and contexts. For example, the basic methodology also could be used to help predict and quantify the likely future impacts of a proposed action. Although the case-specific definition and weighting of value categories will vary, based on factors that include the nature, duration, and magnitude of the experienced losses, we believe that the social, cultural, and nonphysical health components of losses frequently will play a significant role in the overall depiction and calculation of experienced losses. To the extent that results in other communities are similar (an empirical question), then a more comprehensive accounting of the full range of economic, social, health, and cultural impacts will have the implication that, for many Indigenous communities, household economic losses contribute only a relatively small portion of total compensable losses. This implies that the amounts of monetary compensation owing to Indigenous communities with respect to losses experienced as the result of initiatives undertaken (or approved) by provincial, state, or federal governments will often be substantially higher than estimated by conventional measures because of the high importance associated with a range of social, cultural, and nonphysical health and well-being impacts.

Further development of this multiattribute approach, modified as needed by the environment, circumstances, and historical context of each community, will provide the basis for more accurate estimates of Indigenous damages and a closer working relationship between researchers and community members. We hope that the values-focused and more transparent elements of this approach also help to create a basis for the respect, curiosity, and humility that often is sorely lacking as part of attempts to impose a non-native perspective on the evaluation of losses experienced by Indigenous communities.

It is important to note, however, that monetary compensation for losses can only be considered as part of the reparations needed to make up for the multiple dimensions of loss that many Indigenous communities, including the two Dene communities described in this paper, experience as the result of forced exclusion from, or developments on, their traditional lands. Unless a compensation agreement is the product of a meaningful consultation process it can, in some cases, appear to trivialize those losses. Although monetary awards have the potential to provide funds to address damages and aid the healing process, compensation by itself cannot overcome the trauma experienced by past and present community members from a severed way of life, nor will it repair their lost connection to lands, family, ancestors, and place-based knowledge and stories. Those lives and worlds cannot be restored and there is no measure of value for what was lost. 
Responses to this article can be read online at: http://www.ecologyandsociety.org/issues/responses. php/12038

\begin{abstract}
Acknowledgments:
We acknowledge funding support for methods development from the Decision, Risk, and Management Science Program, US National Science Foundation, as part of Award No. 1728807. We thank the legal team and the Dene communities-whose identities remain unstated, pending final agreement on a settlement with Canadafor the trust they placed in us and for their willingness to share so openly and fully with non-Indigenous people whom they had only recently met. We also thank Professor Leslie Robertson (UBC) and researchers with The Firelight Group (Vancouver) for helpful insights regarding the ethnography of Canada's Dene Nations.
\end{abstract}

\section{Data Availability:}

Data collection for this study consisted of interviews with members of North American First Nations and Tribes. The data is confidential per agreements with Tribal members and is exempt from Institutional Review Board review under 45 CFR 46.104(d)2.

\section{LITERATURE CITED}

Ackerman, F., and L. Heinzerling. 2002. Pricing the priceless: cost-benefit analysis of environmental protection. University of Pennsylvania Law Review 150(5):1553-1584. https://doi. org/10.2307/3312947

Alexander, B. K. 2008. The globalization of addiction: a study in poverty of the spirit. Oxford University Press, Oxford, UK. https:// doi.org/10.1093/med/9780199588718.001.0001

Berkes, F. 1999. Sacred ecology: traditional ecological knowledge and resource management. Taylor \& Francis, New York, New York, USA.

Bessette, D. L., and R. Gregory. 2020. The promise and reality of social-cultural metrics. Ecology and Society 25(3):11. https://doi. org/10.5751/ES-11730-250311

Borrows, J. 2002. Recovering Canada: the resurgence of Indigenous law. University of Toronto Press, Toronto, Ontario, Canada.

Brest, P., and L. H. Krieger. 2010. Problem solving, decision making, and professional judgement: a guide for lawyers and policymakers. Oxford University Press, New York, New York, USA.

Brody, H. 1981. Maps and dreams: Indians and the British Columbia frontier. Douglas \& McIntyre, Vancouver, British Columbia, Canada.

Chan, K. M. A., A. D. Guerry, P. Balvanera, S. Klain, T. Satterfield, X. Basurto, A. Bostrom, R. Chuenpagdee, R. Gould, B. S. Halpern, N. Hannahs, J. Levine, B. Norton, M. Ruckelshaus, R. Russell, J. Tam, and U. Woodside. 2012. Where are cultural and social in ecosystem services? A framework for constructive engagement. BioScience 62(8):744-756. https://doi.org/10.1525/ bio.2012.62.8.7
Christie, K. S., T. E. Hollmen, H. P. Huntington, and J. R. Lovvorn. 2018. Structured decision analysis informed by traditional ecological knowledge as a tool to strengthen subsistence systems in a changing Arctic. Ecology and Society 23 (4):42. https://doi.org/10.5751/ES-10596-230442

Coulthard, G. S. 2014. Red skin, white masks: rejecting the colonial politics of recognition. University of Minnesota Press, Minneapolis, Minnesota, USA. https://doi.org/10.5749/ minnesota/9780816679645.001.0001

Department of Indian Affairs. 1952. Indian Affairs Branch memo 23 April 1952. Department of Indian Affairs, Ottawa, Ontario, Canada.

Department of Indian Affairs. 1957. Indian Affairs Branch memo 3 April 1957. Department of Indian Affairs, Ottawa, Ontario, Canada.

Donatuto, J. L., T. A. Satterfield, and R. Gregory. 2011. Poisoning the body to nourish the soul: prioritising health risks and impacts in a Native American community. Health, Risk \& Society 13 (2):103-127. https://doi.org/10.1080/13698575.2011.556186

Elie, P. 2019. What do the church's victims deserve? The New Yorker, 15 April. [online] URL: https://www.newyorker.com/ magazine/2019/04/15/what-do-the-churchs-victims-deserve

Esteves, A. M., D. Franks, and F. Vanclay. 2012. Social impact assessment: the state of the art. Impact Assessment and Project Appraisal 30(1):34-42. https://doi.org/10.1080/14615517.2012.660356

Failing, L., R. Gregory, and P. Higgins. 2013. Science, uncertainty, and values in ecological restoration: a case study in structured decision-making and adaptive management. Restoration Ecology 21(4):422-430. https://doi.org/10.1111/j.1526-100X.2012.00919. $\underline{\mathrm{x}}$

Federal Court of Australia. 2016. Griffiths v Northern Territory of Australia (No 3), [2016] FCA 900. Federal Court of Australia, Sydney, New South Wales, Australia.

Freeman, A. M. III. 2003. The measurement of environmental and resource values: theory and methods. Second edition. Resources for the Future, Washington, D.C., USA.

Gilani, H. R., J. L. Innes, and H. Kent. 2018. Developing human well-being domains, metrics and indicators in an Ecosystembased management context in Haida Gwaii, British Columbia, Canada. Society \& Natural Resources 31(12):1321-1337. https:// doi.org/10.1080/08941920.2018.1481548

Government of Canada. 2012. Canadian Environmental Assessment Act, SC 2012, c. 19, s. 52. Government of Canada, Ottawa, Ontario, Canada.

Graham, C., K. Loffen, and S. Pinto. 2018. Well-being in metrics and policy. Science 362(6412):287-288. http://doi.org/10.1126/ science.aau5234

Gregory, R., D. Easterling, N. Kaechele, and W. Trousdale. 2016. Values-based measures of impacts to Indigenous health. Risk Analysis 36(8):1581-1588. https://doi.org/10.1111/risa.12533

Gregory, R., L. Failing, M. Harstone, G. Long, T. McDaniels, and D. Ohlsen, D. 2012. Structured decision making: a practical guide to environmental management choices. Wiley-Blackwell, Chichester, UK. https://doi.org/10.1002/9781444398557 
Gregory, R., and W. Trousdale. 2009. Compensating aboriginal cultural losses: an alternative approach to assessing environmental damages. Journal of Environmental Management 90(8):2469-2479. https://doi.org/10.1016/j.jenvman.2008.12.019

Haener, M. K., D. Dosman, W. L. Adamowicz, and P. C. Boxall. 2001. Can stated preference methods be used to value attributes of subsistence hunting by Aboriginal people? A case study in northern Saskatchewan. American Journal of Agricultural Economics 83(5):1334-1340. https://doi.org/10.1111/0002-9092.00287

High Court of Australia. 2019. Northern Territory $v \mathrm{Mr} \mathrm{A}$. Griffiths (deceased) and Lorraine Jones on behalf of the Ngaliwurru and Nungali Peoples, [2019] HCA 7. High Court of Australia, Parkes, Australian Capital Territory, Australia.

Indian Claims Commission. 1995. Indian Claims Commission Proceedings. Minister of Supply and Services Canada, Ottawa, Ontario, Canada.

Indigenous and Northern Affairs Canada. 2015. Indian restoration system database. Indigenous and Northern Affairs Canada, Gatineau, Québec, Canada. [online] URL: https://www. aadnc-aandc.gc.ca/eng/1353081939455/1353082011520

Johansson, P.-O., and B. Kristrom. 2018. Cost-benefit analysis. Cambridge University Press, Cambridge, UK. https://doi. org/10.1017/9781108660624

Kahneman, D. 2011. Thinking, fast and slow. Farrar, Straus \& Giroux, New York, New York, USA.

Keeney, R. L. 1982. Decision analysis: an overview. Operations Research 30(5):803-838. https://doi.org/10.1287/opre.30.5.803

Keeney, R. L., and H. Raiffa. 1993. Decisions with multiple objectives. Cambridge University Press, Cambridge, UK. https:// doi.org/10.1017/CBO9781139174084

Kirkwood, C. W., and R. K. Sarin. 1980. Preference conditions for multi-attribute value functions. Operations Research 28 (1):225-232. https://doi.org/10.1287/opre.28.1.225

Kirmayer, L. J., J. P. Gone, and J. Moses. 2014. Rethinking historical trauma. Transcultural Psychiatry 51(3):299-319. https:// doi.org/10.1177/1363461514536358

Kotaska, J. 2013. Reconciliation "at the end of the day": decolonizing territorial governance in British Columbia after Delgamuukw. Dissertation. University of British Columbia, Vancouver, British Columbia, Canada.

Legat, A. 2012. Walking the land, feeding the fire: knowledge and stewardship among the Tlicho Dene. University of Arizona Press, Tucson, Arizona, USA.

Lichtenstein, S., and P. Slovic. 2006. The construction of preference. Cambridge University Press, New York, New York, USA. https://doi.org/10.1017/CBO9780511618031

Litchfield, J. 1999 Compensation for loss or impairment of Native title rights and interests. Australian Mining and Petroleum Law Journal 18:253-266.

O'Faircheallaigh, C. 2008. Negotiation cultural heritage? Aboriginal-mining company agreements in Australia. Development and Change 39(1):25-51. https://doi.org/10.1111/j.1467-7660.2008.00467. $\underline{x}$
Office of the President of the United States. 1981. U.S. Executive Order No. 12291, 3 CFR 127, 1981. Office of the President of the U.S., Washington, D.C., USA.

Office of the Treaty Commissioner. 1907. Treaty 10. Office of the Treaty Commissioner, Saskatoon, Saskatchewan, Canada.

Ogden, A. E., and J. L. Innes. 2009. Application of structured decision making to an assessment of climate change vulnerabilities and adaptation options for sustainable forest management. Ecology and Society 14(1):11. https://doi. org/10.5751/ES-02771-140111

Raiffa, H. 2002. Negotiation analysis: the science and art of collaborative decision making. Belknap, Cambridge, Massachusetts, USA.

Sahlins, M. 1999. Two or three things that I know about culture. Journal of the Royal Anthropological Institute 5(3):399-421. https://doi.org/10.2307/2661275

Satterfield, T., R. Gregory, S. Klain, M. Roberts, and K. M. Chan. 2013. Culture, intangibles and metrics in environmental management. Journal of Environmental Management 117:103-114. https://doi.org/10.1016/j.jenvman.2012.11.033

Satz, D. 2010. Why some things should not be for sale: the moral limits of markets. Oxford University Press, New York, New York, USA.

Sharp, H. S. 2004. Loon: memory, meaning, and reality in a Northern Dene community. University of Nebraska Press, Lincoln, Nebraska, USA.

Shephard, K., D. Hubbard, N. Fenton, K. Claxton, E. Leudeling, and J. de Leeuw. 2015. Development goals should enable decisionmaking. Nature 523(7559):152-154. https://doi.org/10.1038/523152a

Simpson, L. B. 2014. Land as pedagogy: Nishnaabeg intelligence and rebellious transformation. Decolonization: Indigeneity, Education \& Society 3(3).

Slovic, P. 2010. The feeling of risk: new perspectives on risk perception. Earthscan, London, UK. https://doi.

org/10.4324/9781849776677

Specific Claims Tribunal Canada. 2016. Huu-Ay-Aht First Nations v. Her Majesty the Queen in Right of Canada, [2016] SCTC 14. Specific Claims Tribunal Canada, Ottawa, Ontario, Canada.

Statistics Canada. 2019. Consumer price index, annual average, not seasonally adjusted: Table 18-10-0005-01. Statistics Canada, Ottawa, Ontario, Canada. https://doi.org/10.25318/1810000501eng

Supreme Court of Canada. 1997. Delgamuukw v. British Columbia, [1997] 3 SCR 1010. Supreme Court of Canada, Ottawa, Ontario, Canada.

Thira, S., and R. McCormick. 2012. Opinion: Are Aboriginal teens dying to belong? Vancouver Sun, 18 December. [online] URL: http://www.vancouversun.com/technology/Opinion+aboriginal+ teens+dying+belong/7717402/story.html

Tobias, J. K., and C. A. M. Richmond. 2014. "That land means everything to us as Anishinaabe....": environmental dispossession 
and resilience on the North Shore of Lake Superior. Health \& Place 29:26-33. https://doi.org/10.1016/j.healthplace.2014.05.008

Turner, N. J. 2005. The Earth's blanket: traditional teachings for sustainable living. University of Washington Press, Seattle, Washington, USA.

Turner, N. J., R. Gregory, C. Brooks, L. Failing, and T. Satterfield. 2008. From invisibility to transparency: identifying the implications. Ecology and Society 13(2):7. https://doi. org/10.5751/ES-02405-130207

Tversky, A., S. Sattath, and P. Slovic. 1988. Contingent weighting in judgment and choice. Psychological Review 95(3):371-384. https://doi.org/10.1037/0033-295X.95.3.371

U.S. Department of Interior. 2018. Natural resource damage assessment and restoration in the Tribal context. Office of Policy Analysis, Washington, D.C., USA.

von Winterfeldt, D., and W. Edwards. 1986. Decision analysis and behavioral research. Cambridge University Press, Cambridge, Massachusetts, USA.

Wilson, S. 2008. Research is ceremony: Indigenous research methods. Fernwood, Halifax, Nova Scotia, Canada. 